\title{
INQUIRY INTO VERTICAL MOVEMENTS OF THE EARTH'S CRUST BASED ON SAMPLES FROM EASTERN LITHUANIA
}

\author{
Ruta Puziene ${ }^{1}$, Asta Anikeniene ${ }^{2}$, Gitana Karsokiene ${ }^{3}$ \\ ${ }^{1}$ Department of Geodesy and Cadastre, Faculty of Environmental Engineering, \\ Vilnius Gediminas Technical University, Sauletekio al. 11, 10223 Vilnius, Lithuania \\ ${ }^{2}$ Department of Geodesy, Civil Engineering Faculty, Vilnius University of Applied Engineering Sciences, \\ Antakalnio g. 54, 10303 Vilnius, Lithuania \\ ${ }^{3}$ IH Soros International House, Konstitucijos pr. 23, 08105 Vilnius,, Lithuania \\ E-mails: ${ }^{1}$ ruta.puziene@vgtu.lt (correspondingauthor); ${ }^{2}$ asta.anikeniene@gmail.com; \\ 3gitana.karsokiene@gmail.com
}

Received 06 January 2014; accepted 10 June 2014

\begin{abstract}
In the research of vertical movements of the earth's crust, examination of statistical correlations between the measured vertical movements of the earth's crust and territorial geo-indexes is accomplished with the help of mathematical statistical analysis. Availability of the precise repeated levelling measuring data coupled with the preferred research methodology offer a chance to determine and predict recent vertical movements of the earth's crust. For the inquiry into recent vertical movements of the earth's crust, a Lithuanian class I vertical network levelling polygon was used. Drawing on measurements made in the polygon, vertical velocities of earth's crust movements were calculated along the following levelling lines. For determining the relations shared by vertical movements of the earth's crust and territorial geo-parameters, the following territory-defining parameters are accepted. Examination of the special qualities of relations shared by vertical movements of the earth's crust and geo-parameters in the territory under research contributed to the computation of correlation matrices. Regression models are worked out taking into consideration only particular territory-defining geo-parameters, i.e. only those parameters which exhibit the following correlation coefficient value of the vertical earth's crust movement velocity: $r \geq 0.50$. A forecast of the velocities pertaining to vertical movements of the earth's crust in the territory under examination was made with the application of regression models. Further in the process of this research, a map was compiled specifying the velocities of vertical movements of the earth's crust in the territory. In the eastern part of this territory, the earth's crust rises at a rate of up to $3 \mathrm{~mm}$ /year; while in the western part of it, the earth crust lowers at a rate of up to $-1.5 \mathrm{~mm} /$ year. In order to pinpoint territories characterised by temperate and regular rising/lowering or intensive rising/lowering, a map of horizontal gradients of recent vertical earth crust movements in the territory enclosed by levelling polygon was compiled.
\end{abstract}

Keywords: geodetic levelling line, recent vertical movements of the earth's crust, correlation analysis, regression analysis, horizontal gradients of vertical movements of the earth's crust, geo-indexes of the territory, repeated geodetic measurements.

Reference to this paper should be made as follows: Puziene, R.; Anikeniene, A.; Karsokiene, G. 2014. Inquiry into vertical movements of the earth's crust based on samples from eastern Lithuania, Geodesy and Cartography 40(2): $58-67$.

\section{Introduction}

Not only earthquakes account for movements of the earth's crust; slow periodic rising/lowering of the earth's crust is also observed (Schwartz 2007). In addition to geologic methods, the geodetic ones can be used for the research of recent vertical movements of the earth's crust. Data provided by precise repeated geodetic measuring can offer a picture of geodynamic processes taking place within the entire territory of a country. However, measurements taken along the levelling lines may be affected by the influences of non-tectonic origin, such as seasonal fluctuations of the groundwater level (Demoulin 2004) or the factors of anthropogenic origin (Zakarevičius 1994; Tosi et al. 2007). When applying various research methodologies, it is vital to distinguish between effects produced by the factors of 
either tectonic or non-tectonic origin on the measurements. To gain a better insight into recent vertical movements of the earth's crust obtained by geodetic measuring or for pinpointing more precisely the component of tectonic origin, different methodologies are applied. Besides, the geologic structure of a locality and fractures found in it are taken into account. This not only allows determining the developmental tendencies pertaining to the earth's crust but also settling a number of other issues related to recent tectonic movements and seismic tectonics (Zakarevičius 1994, 2003; Fukahata et al. 1996; Bonaccorso, Mattia 2000; Mrlina 2000; Li et al. 2001; Bonaccorso 2002; Battaglia et al. 2003a, 2003b; Howle et al. 2003; Langbein 2003; Nielsen, Bayer 2003; Demoulin 2004; Lanari et al. 2004; Amoruso et al. 2005; Behncke et al. 2006; Gottsman et al. 2006; Newman et al. 2006; Vestol 2006; Tosi et al. 2007).

Availability of the precise repeated levelling measuring data coupled with the preferred research methodology offer a chance to determine and predict recent vertical movements of the earth's crust. They may be represented graphically by maps of recent vertical movements of the earth's crust. These maps are compiled following the estimation of digital values pertaining to recent vertical movements of the earth's crust.

By means of mathematical statistics analysis, the present study purposes to inquire into recent vertical movements of the earth's crust determined with the help of measuring; to predict vertical movements of the earth's crust in a selected territory and to estimate their intensity rate by using territorial geo-parameters (in this study, geo-parameters mean the geologic characteristics observed within a definite territory).

\section{Methodology of the research}

Vertical movements of the earth's crust are determined by geodetic methods, drawing on the findings provided by repeated measuring of geodetic levelling. Velocities of vertical movements of the earth's crust are estimated by the following equation:

$$
v_{i j}=\frac{h_{i j}^{\prime \prime}-h_{i j}^{\prime}}{\Delta t},
$$

where $h_{i j}^{\prime}, h^{\prime \prime}{ }_{i j}$ are the altitude differences between $i$ and $j$ geodetic marks recorded during the first and second measuring, $\Delta t$ is the period of time dividing repeated levelling.

Basing on the findings of measuring taken along the levelling line, vertical velocities of movements of the earth's crust with respect to the initial point of the line are estimated by the following equation:

$$
v_{k}=\sum_{i=1}^{k} v_{i-1, i},
$$

where $i=0,1, \ldots, k$ are the numbers of geodetic points.

Movements of the earth's crust measured by geodetic methods are the parameters of the general condition of a natural system. In order to study relations shared by vertical movements of the earth's crust and geo-parameters, all-round research is carried out, including the integrated analysis of territorial geo-parameters and data provided by geodetic measuring of recent movements of the earth's crust.

Initial estimation of relations shared by measured recent vertical movements of the earth's crust and territorial geo-parameters is performed by calculating the correlation coefficients for the values of measured vertical movements of the earth's crust and for the digital values of territory-defining geo-parameters (Rodionov 1981; Draper, Smith 1998; Spiegel, Stephens 2007):

$$
r_{i j}=\frac{\sigma_{i j}}{\sqrt{\sigma_{i i} \cdot \sigma_{j j}}},
$$

where $\sigma_{i j}$ are the elements of a covariant matrix; $\sigma \mathrm{ii}, \sigma \mathrm{jj}$ are the dispersions of random values.

Mathematical statistical interactions involving all parameters are defined by a matrix of correlation coefficients (Krumbein, Graybill 1965; Spiegel, Stephens 2007).

Identified with vertical shifts of the earth's crust and shift velocities, the measured vertical shifts of geodetic marks and their respective velocities represent the algebraic sum of movements originating from nontectonic sources, i.e. movements accounted for by various natural or anthropogenic factors. In order to eliminate local anomalies triggered by accidental causes, to determine the regular trend and to verify its adequacy for the measuring findings, mathematical statistical methods are applied. Well suited for the study of the regular character of earth's crust movements along the levelling lines, regression analysis is one of such methods. A forecast model may be expressed as follows (Draper, Smith 1998; Spiegel, Stephens 2007):

$$
V=\beta_{0}+\beta_{1} X_{1}+\beta_{2} X_{2}+\ldots+\beta_{m} X_{m}+\varepsilon,
$$

where $X_{1}, \ldots, X_{m}$ are the values of territory-defining geo-parameters.

The regression model's conformance to the findings obtained by measuring is verified by applying the following regression suitability rates: determination coefficient $R^{2}$ and Fisher statistics (Draper, Smith 1998; Spiegel, Stephens 2007). 
F statistics are calculated for the estimation of the created regression model's adequacy for the measured velocities of vertical movements of the earth's crust along the route under examination.

$$
F=\frac{\left(\hat{\beta} X^{T}-n \bar{v}^{2}\right)(n-m-2)}{\left(X^{T} X-\hat{\beta} X^{T} V\right)(m-1)},
$$

where $\bar{v}$ is the mean value of the dependent variable on the line under examination, $n$ is the number of geodetic marks, $m$ is the power of a polynomial.

$F$ statistics have the $k_{1}=m-1$ and $k_{2}=n-m-2$ degrees of freedom. If $F>F_{q\left(k_{1}, k_{2}\right)}$, then it is possible to argue, with a probability of $p=1-q$, that values obtained by using the regression model are adequate for the values of measured vertical movements of the earth's crust, i.e. the trend of movements of the earth's crust described by the regression model is adequate for the actual physical process determined by measuring. If $F<F_{q\left(k_{1}, k_{2}\right)}$, then it is possible to state, with a probability of $p=1-q$, that the regression model is out of conformance with the actual movement model, i.e. it fails to reflect adequately the on-going actual movements of the earth's crust; consequently, it is not applicable.

The greater the proximity of the determination coefficient to one and the greater the lower limit of its reliability interval, the greater is the efficaciousness of the regressive model. The lower limit of the determination coefficient is estimated by the following equation (Draper, Smith 1998; Spiegel, Stephens 2007):

$$
R_{\min }^{2}=R^{2}(m)-2 \sqrt{\frac{2 m(n-m-1)}{(n-1)\left(n^{2}-1\right)}}\left(1-R^{2}(m)\right) .
$$

Derivatives of these movements are vitally important for the study of recent movements of the earth's crust. The most important of them is the gradient characterising the velocity of earth's crust deformations.

Possessing only a graphic image of the field of recent vertical movements of the earth's crust (a map of the velocities of vertical movements of the earth's crust) or the digital values of these movements at relevant points, the values of the horizontal gradients of movement velocities can be found by digital differentiation methods (Ulomov 2004). Assuming that the changes of vertical movements of the earth's crust between iso-lines $V_{i}$ and $V_{i+1}$ and the distance between them $D_{i, i+1}$ has a linear character, the gradient's digital values are calculated by the following equation:

$$
|\operatorname{grad} V|=\frac{\left(V_{i+1}-V_{i}\right)}{D_{i, i+1}} .
$$

\section{Results}

For the inquiry into recent vertical movements of the earth's crust, a Lithuanian class I vertical network $4^{\text {th }}$ levelling polygon (as shown in Fig. 1) was selected.

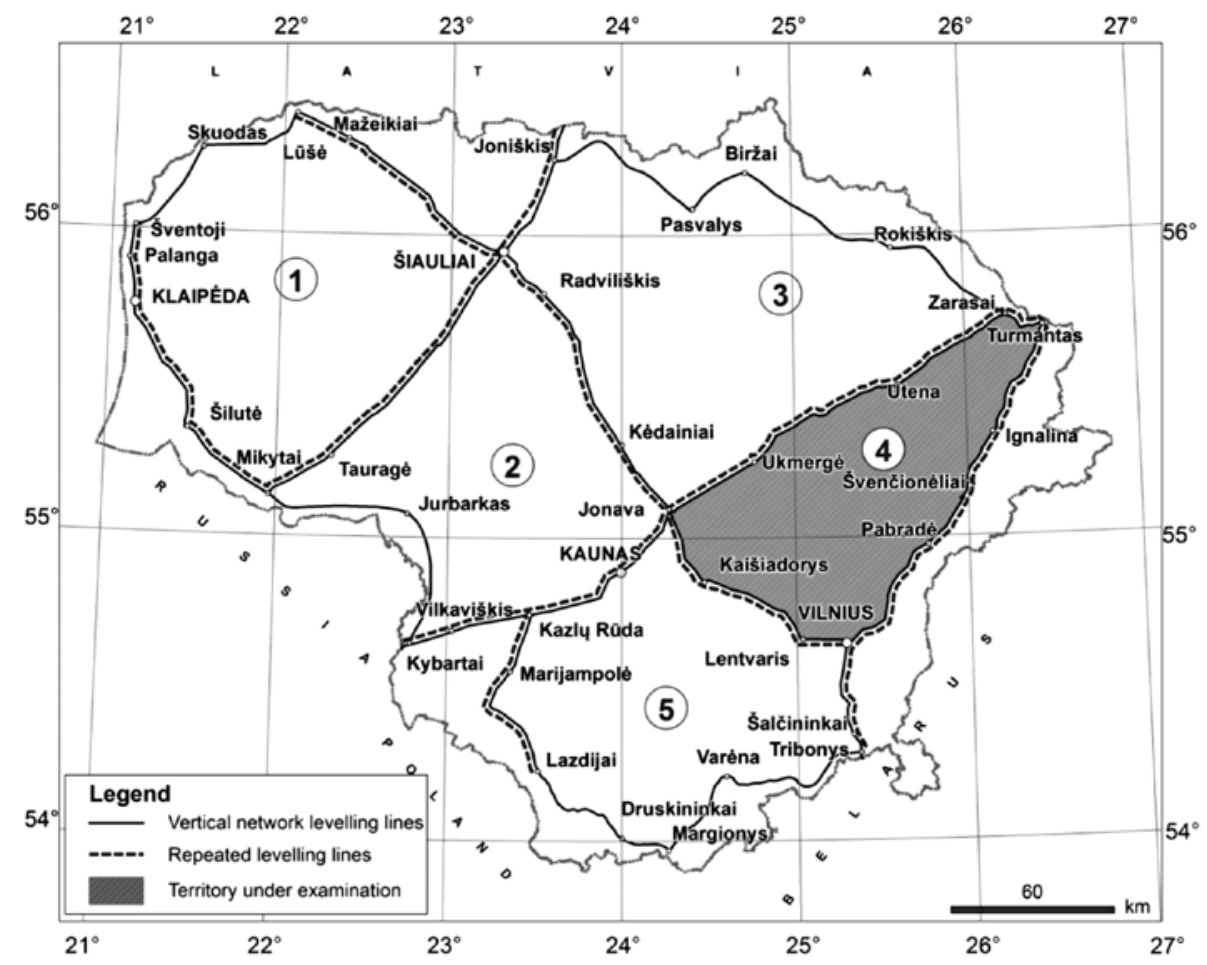

Fig. 1. Accuracy class I network created for the territory of Lithuania over 1998-2006 (with polygons marked on it) 
The levelling polygon is composed of the following levelling lines: Jonava-Zarasai-Turmantas, Turmantas-Vilnius, Vilnius-Jonava. They were measured in different years by different enterprises, from 1934 to 2006. A period between the last two repeated levellings was chosen for the research. Characteristics of the levellings of this polygon are given in Table 1 .

Drawing on data collected by measurements conducted in the polygon, vertical velocities of earth's crust movements were calculated along the following levelling lines in the following periods:

-Vilnius-Jonava, 1970/71-1998;

- Jonava-Zarasai-Turmantas, 1980-2005;

- Turmantas-Vilnius, 1985/87-2005/06.

For determining the relations shared by vertical movements of the earth's crust and territorial geo-parameters, the following territory-defining parameters are accepted:

$x_{1}$ - gravitational field;

$x_{2}$ - magnetic field;

$x_{3}$ - current relief of the earth's crust;

$x_{4}$ - crystalline basement relief;

$x_{5}$ - pre-Quaternary (main layers) relief;

$x_{6}$ - Quaternary cover thickness;

$x_{7}$ - sedimentary cover thickness;

$x_{8}$ - pre-Quaternary (main layers) cover thickness.

Values of the geo-parameters were determined on the grounds of benchmark co-ordinates from the digital database.

Availability of data on vertical movements (they are identified with movements of the earth's crust) measured along repeated levelling lines and of the digital values of geo-parameters enables the application of a mathematical statistical analysis. Examination of the special qualities of relations shared by vertical movements of the earth's crust and geo-parameters in the territory under research contributed to the computation of correlation matrices along the following lines: Vilnius-Jonava, Jonava-Zarasai-Turmantas, Turmantas-Vilnius, and by bringing these lines into a single unit, i.e. for one common polygon Vilnius-Jonava-Zarasai-Turmantas-Vilnius.

Coefficients of correlation between measured velocities of vertical movements of the earth's crust and territorial geo-parameters are provided in Table 2.

Findings provided in Table 2 indicate that not all correlation dependencies are sufficiently strong. Obviously, the strongest correlative relationships between vertical movements of the earth's crust movements and all geo-parameters, with the exception of
Table 1. Characteristics of the levelling lines

\begin{tabular}{|l|c|c|c|}
\hline \multicolumn{4}{|c|}{ Levelling line } \\
\hline & $\begin{array}{c}\text { Vilnius- } \\
\text { Jonava }\end{array}$ & $\begin{array}{c}\text { Jonava- } \\
\text { Zarasai- } \\
\text { Turmantas }\end{array}$ & $\begin{array}{c}\text { Turmantas- } \\
\text { Vilnius }\end{array}$ \\
\hline Period, years & $\begin{array}{c}1970 / 71- \\
1998\end{array}$ & $1980-2005$ & $\begin{array}{c}1985 / 87- \\
2005 / 06\end{array}$ \\
\hline $\begin{array}{l}\text { Measuring } \\
\text { duration, years }\end{array}$ & $27 / 28$ & 25 & $19 / 21$ \\
\hline $\begin{array}{l}\text { Line length, } \\
\text { km }\end{array}$ & 103 & 156 & 164 \\
\hline $\begin{array}{l}\text { Number of } \\
\text { repeatedly le- } \\
\text { velled geodetic } \\
\text { marks }\end{array}$ & 14 & 26 & 26 \\
\hline $\begin{array}{l}\text { Accuracy, } \\
\text { mm/km }\end{array}$ & $0.36-0.53$ & $0.38-0.62$ & $0.68-0.69$ \\
\hline
\end{tabular}

Table 2. Findings of the correlation analysis

\begin{tabular}{|c|c|c|c|c|c|c|c|}
\hline$r\left(v x_{1}\right)$ & $r\left(v x_{2}\right)$ & $r\left(v x_{3}\right)$ & $r\left(v x_{4}\right)$ & $r\left(v x_{5}\right)$ & $r\left(v x_{6}\right)$ & $r\left(v x_{7}\right)$ & $r\left(v x_{8}\right)$ \\
\hline \multicolumn{7}{|c|}{ Line / Polygon } \\
\hline \multicolumn{7}{|c|}{ Vilnius-Jonava } \\
\hline 0.25 & 0.07 & 0.89 & 0.88 & 0.77 & 0.64 & -0.85 & -0.85 \\
\hline \multicolumn{7}{|c|}{ Jonava-Zarasai-Turmantas } \\
\hline 0.31 & -0.11 & 0.89 & 0.12 & 0.80 & 0.62 & 0.44 & 0.32 \\
\hline \multicolumn{7}{|c|}{ Turmantas-Vilnius } \\
\hline-0.86 & -0.31 & 0.69 & -0.94 & 0.22 & 0.45 & 0.93 & 0.95 \\
\hline \multicolumn{7}{|c|}{ Vilnius-Jonava-Zarasai-Turmantas-Vilnius } \\
\hline-0.69 & 0.02 & 0.29 & -0.57 & 0.45 & -0.03 & 0.70 & 0.67 \\
\hline
\end{tabular}

gravitational field and magnetic field $R \leq 0.25$, exist along the Vilnius-Jonava line. The Jonava-ZarasaiTurmantas line demonstrates the strongest correlative relationships with the current earth's crust relief, preQuaternary (main layers) relief, and Quaternary cover thickness $0.62 \leq R \leq 0.89$. Along the Turmantas-Vilnius line, vertical movements of the earth's crust exhibit the strongest correlative relationships with the gravitational field, the current earth's crust relief, crystalline basement relief, sedimentary cover thickness and pre-Quaternary (main layers) cover thickness $-0.94 \leq R \leq 0.95$. When all these lines are brought together to form a closed polygon, the strongest correlative relations are observed with the gravitational field, crystalline basement relief, pre-Quaternary (main layers) relief, sedimentary cover thickness and pre-Quaternary (main layers) cover thickness $-0.57 \leq R \leq 0.70$.

Moreover, findings provided in Table 2 show that coefficients of correlation with certain identical geoparameters are significant along all lines; however, along some particular lines they are not significant. 
This can be accounted for by the specific qualities of the territory's geological structure.

The following conclusions emerge from the findings of this research: the structure and strength of relations shared by measured vertical movements of the earth's crust and territorial geo-parameters is related to the territorial peculiarities. Along different lines, the coefficients of vertical movements' correlation with the same parameters are different. Along separate lines, the values of correlative dependencies are stronger compared to the values characterising the polygon enclosed by the lines. It is possible to conclude that the working out of regression models demands taking into account the non-homogeneous character of the geologic structure of the territory. From the territorial point of view, the geologic structure of Lithuania is heterogeneous. Thus, it is not possible to interpret geodetic measurements adequately unless parameters characteristic to a particular region and connected with the tectonic development of the territory are taken into consideration. Also, it is possible to argue that recent movements of the earth's crust taking place in the north-eastern part of Lithuania represent a natural continuation of the development of geologic processes. This means that there is a realistic chance to forecast basic features of the on-going tectonic processes and to characterise the current tectonic background basing upon the geologic and geophysical parameters of the territory.

A regression model can be applied for working out a tectonic background forecast for a particular territory. In this model, territorial geo-parameters serve as causal variables. Having vertical movements computed on the grounds of the repeated levelling line measuring data (movements are identified with movements of the earth's crust) and the digital values of territorial geo-parameters, is possible to produce regression models. Regression models are worked out taking into consideration only particular territory-defining geo-parameters, i.e. only those parameters which exhibit the following correlation coefficient value of the vertical earth's crust movement velocity: $r \geq 50$. In order to estimate the adequacy of regression models, determination coefficient $R^{2} \%$, statistics $F$ and $F_{q\left(k_{1}, k_{2}\right)}$, where $q=0.05$ was computed.

Rates of the regression models for separate levelling lines and the polygon enclosed by these lines as well as the rates of models' adequacy to the findings of measuring are given in Table 3.

Data from Table 3 allow making a conclusion that uneven distribution of geo-parameters along separate levelling lines substantiate the assumption that relations shared by geo-parameters and movements of the earth's crust are not homogeneous all over the territory. Estimation of regression models' adequacy to the findings provided by measuring in Vilnius-JonavaZarasai-Turmantas-Vilnius levelling polygon shows that estimation results are somewhat poorer compared to the ones supplied by separate lines. In all cases, the determination rate is higher than $76 \%$.

Since regressive models of vertical movements of the earth's crust are adequate to the findings provided by measuring, the models can be applied for the forecasting of movements of the earth's crust not only along repeated levelling lines but also in polygons enclosed by the repeated levelling lines, i.e. in areas where geodetic measurements are missing. Such methodology allows avoiding subjective estimation of geoparameters when a map of vertical movements of the

Table 3. Results of the regression analysis

\begin{tabular}{|c|c|c|c|c|}
\hline $\begin{array}{c}\text { Pos. } \\
\text { No }\end{array}$ & Regression models & $R^{2}, \%$ & $F$ & $F_{q\left(k_{1}, k_{2}\right)}$ \\
\hline \multicolumn{5}{|c|}{ Vilnius-Jonava } \\
\hline 1 & $\begin{array}{c}V=2.914-7.705 \cdot 10^{-2} \cdot x_{3}+10.016 \cdot 10^{-2} \cdot x_{4}-3.148 \cdot 10^{-2} \cdot x_{5}+3.297 \cdot 10^{-2} \cdot x_{6}+3.846 \cdot 10^{-2} \cdot x_{7}+ \\
5.757 \cdot 10^{-2} \cdot x_{8}\end{array}$ & 94.84 & 21.46 & 3.87 \\
\hline \multicolumn{5}{|c|}{ Jonava-Zarasai-Turmantas } \\
\hline 2 & $V=-1.499+7.895 \cdot 10^{-2} \cdot x_{3}-4.980 \cdot 10^{-2} \cdot x_{5}-4.709 \cdot 10^{-2} \cdot x_{6}$ & 80.27 & 29.84 & 3.05 \\
\hline \multicolumn{5}{|c|}{ Turmantas-Vilnius } \\
\hline 3 & $V=-5.378-5.065 \cdot 10^{-2} \cdot x_{1}-1.436 \cdot 10^{-2} \cdot x_{3}+0.880 \cdot 10^{-2} \cdot x_{4}-3.727 \cdot 10^{-2} \cdot x_{7}+6.070 \cdot 10^{-2} \cdot x_{8}$ & 96.00 & 96.04 & 2.71 \\
\hline \multicolumn{5}{|c|}{ Vilnius-Jonava-Zarasai-Turmantas-Vilnius } \\
\hline 4 & $V=-6.562-3.333 \cdot 10^{-2} \cdot x_{1}-0.251 \cdot 10^{-2} \cdot x_{4}+3.405 \cdot 10^{-2} \cdot x_{6}+1.390 \cdot 10^{-2} \cdot x_{7}-0.909 \cdot 10^{-2} \cdot x_{8}$ & 76.20 & 39.06 & 2.35 \\
\hline
\end{tabular}




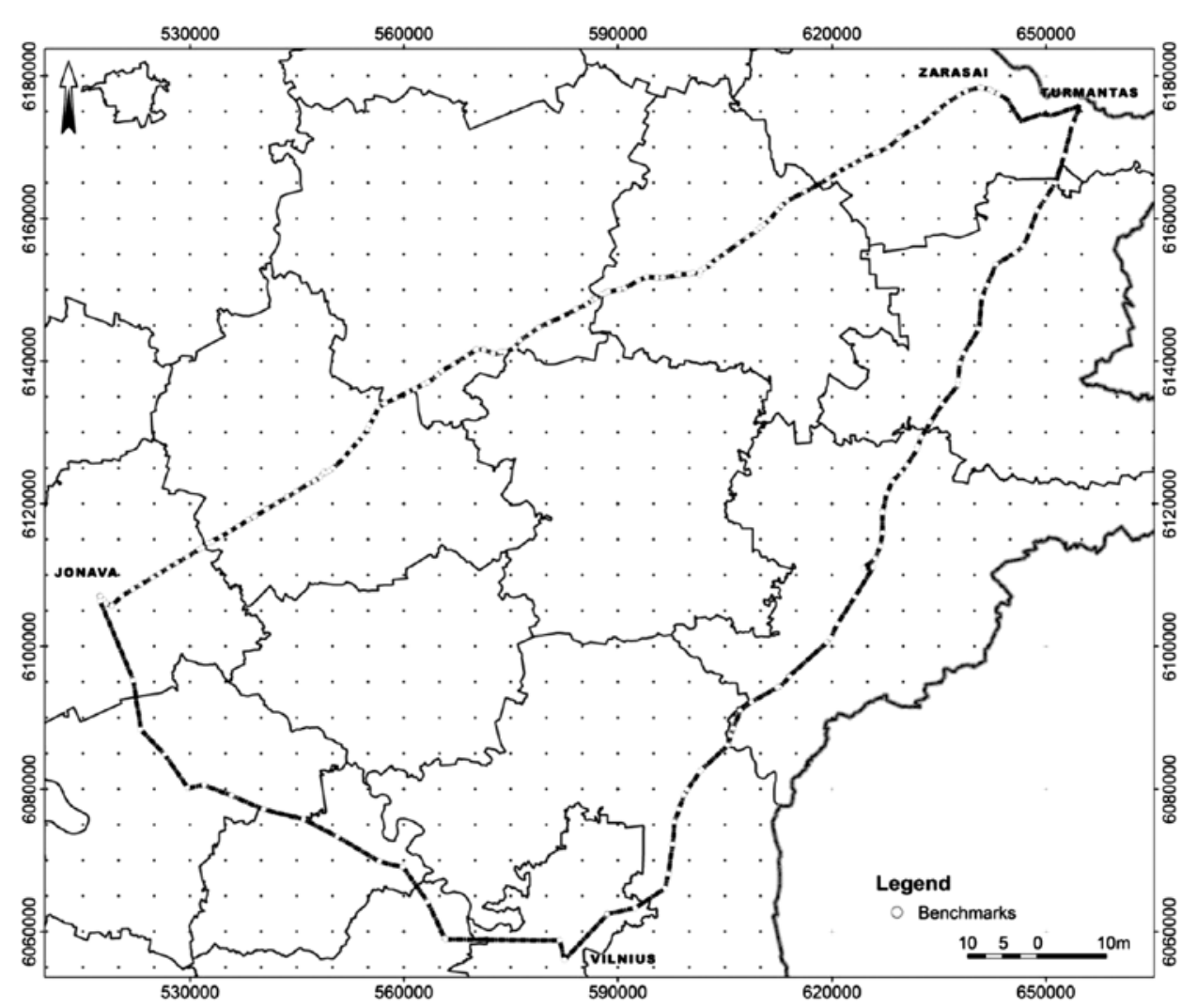

Fig. 2. In Vilnius-Jonava-Zarasai-Turmantas-Vilnius polygon, points are spread using a 5'5 km pattern. At these point values of vertical movement of the earth's crust velocities were predicted

earth's crust is compiled. A forecast of the velocities of vertical movements of the earth's crust in the territory under examination was made with the application of regression models (as shown in Table 3, model (4)). In order to forecast velocities of vertical movements of the earth's crust, the values of independent variables (geo-parameters) involved in the regression equations were determined with the help of digital geologic databases at discrete points positioned at the apexes of a $5 \times 5 \mathrm{~km}$ square grid (as shown in Fig. 2). In total, 469 digital values ranging from -1.84 to $3.18 \mathrm{~mm}$ /year were computed.

Scatter of the digital values of vertical movement velocities throughout the territory enclosed by Vilnius-Jonava-Zarasai-Turmantas-Vilnius polygon is shown graphically in Fig. 3. As can be seen, dispersion of the digital values of velocities is rather even. Scatter range is 5.0231 .

As can be seen from the histogram (Fig. 3), the greatest number of digital values representing vertical movements of the earth's crust fluctuates within the range from -1.3 to $2.7 \mathrm{~mm} /$ year. This circumstance invites a conclusion that in the territory enclosed by the polygon, the digital values of recent vertical movements of the earth's crust vary within these limits, i.e. they are the

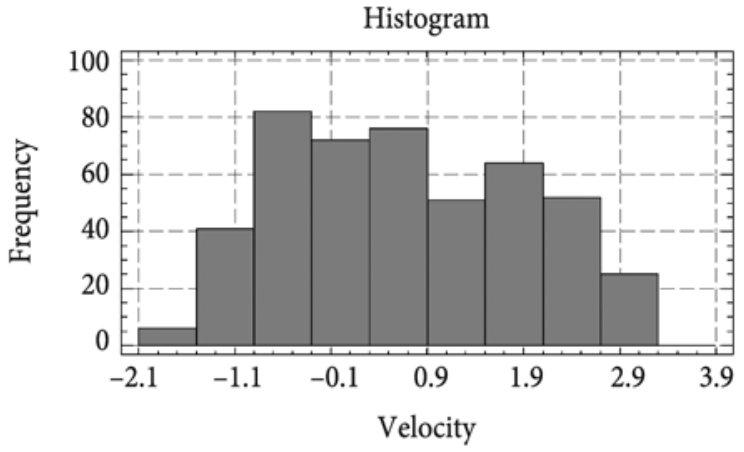

Fig. 3. Frequency of the repetition of digital values of velocities in Jonava-Zarasai-Turmantas-Vilnius polygon

dominant movement velocities in the territory. Mean digital value of the velocities of vertical movements of the earth's crust in the territory enclosed by the levelling polygon is $0.66 \mathrm{~mm} /$ year; median is $0.5128 \mathrm{~mm}$ /year. Dispersion of the existing movement sample is 1.54556 , and the standard error is 1.2432 .

Further in the process of this research, a map of the velocities of vertical movements of the earth's crust in the territory enclosed by Vilnius-Jonava-Zarasai-Turmantas-Vilnius polygon was compiled (as shown in Fig. 4). As indicated in Fig. 4, in the eastern part of this territory, the earth's crust rises at a rate of up to $3 \mathrm{~mm}$ /year takes 


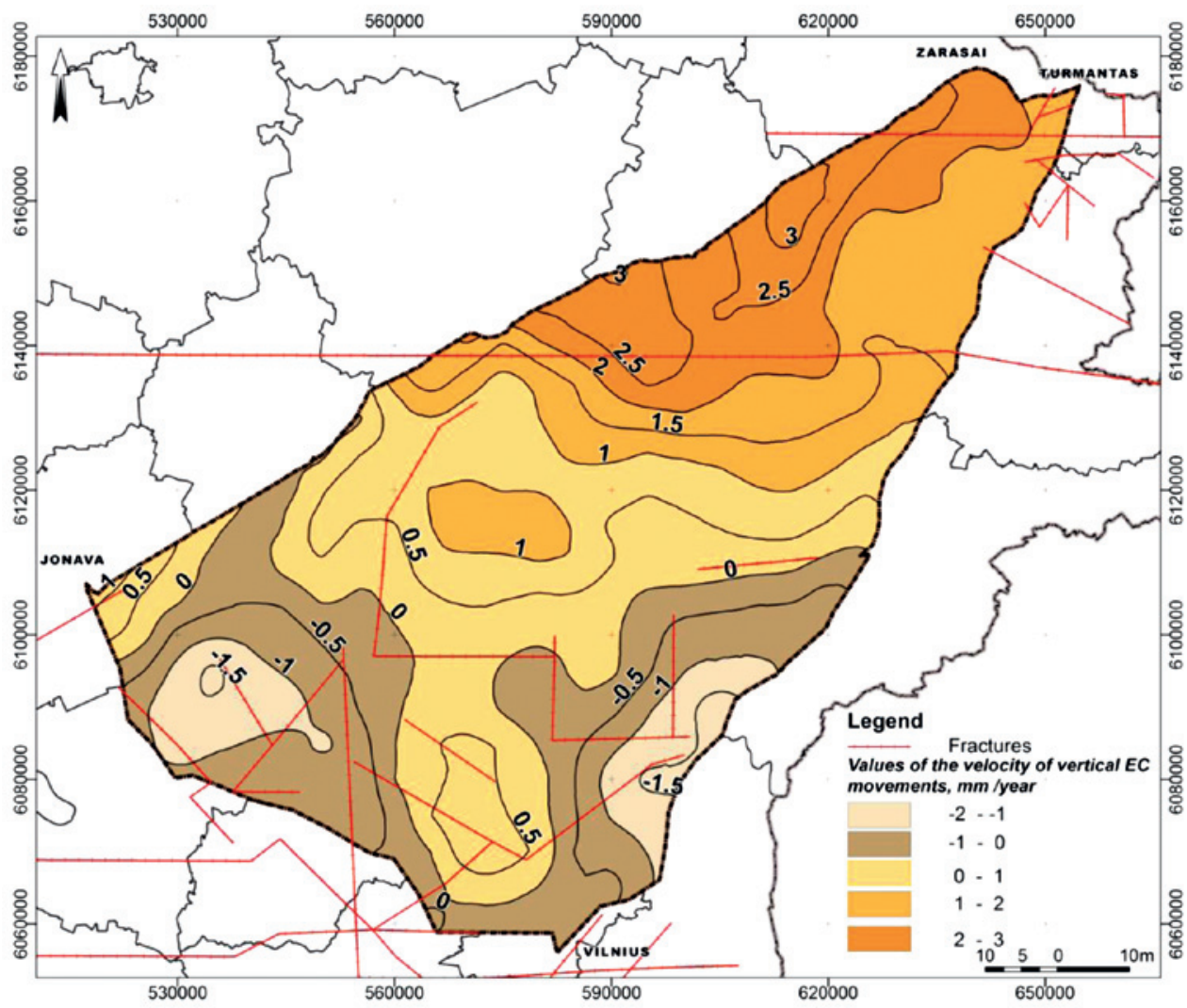

Fig. 4. Velocities (mm/year) of recent vertical movements of the earth's crust in the territory enclosed by Vilnius-Jonava-Zarasai-Turmantas-Vilnius levelling polygon

place; while in the western part of it, the Earth crust lowers at a rate of up to $-1.5 \mathrm{~mm} /$ year.

For the purpose of examining the intensity of changes in the velocities of recent vertical movements of the Earth's crust, the digital values of their horizontal gradients were computed. Higher digital values of gradients in the territory may point to places of more intense tectonic activity, i.e. the places where the movement velocity changes are more intense, or where the movement velocity contrasts are sharper or where the earth's crust rises or lowers more abruptly.

Changes of the digital values of horizontal gradient modules in the territory enclosed by

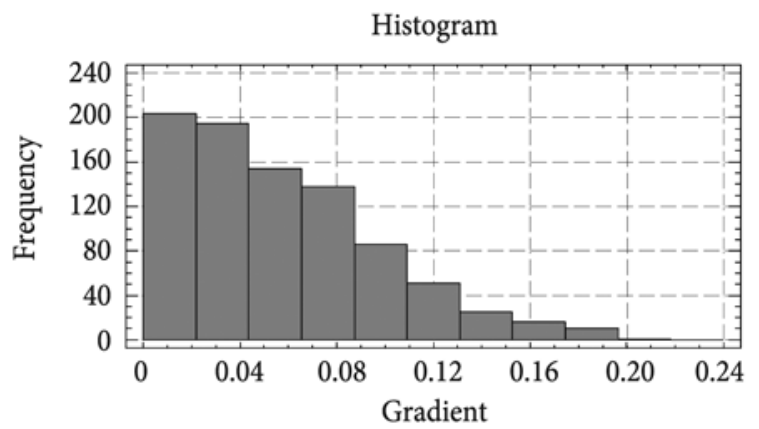

Fig. 5. Frequency of the gradient digital value repetition in Vilnius-Jonava-Zarasai-Turmantas-Vilnius polygon
Vilnius-Jonava-Zarasai-Turmantas-Vilnius polygon range from 0.00006 to $0.20(\mathrm{~mm} /$ year $) / \mathrm{km}$. Scatter of the digital values of gradients over the territory is represented graphically in Fig. 5. As can be seen, dispersion of digital values changes not too evenly: the greatest concentrations occur in places where digital values range from 0 to $0.09(\mathrm{~mm} /$ year $) / \mathrm{km}$. Scatter range is 0.20 .

The histogram indicates the dominance of the gradient module digital values ranging from 0 to 0.10 $(\mathrm{mm} /$ year $) / \mathrm{km}$ in the polygon. Other largely sporadic values do not cover any significant part of the territory. Mean of the digital values of recent vertical earth's crust movement gradients is $0.06(\mathrm{~mm} /$ year $) / \mathrm{km}$, median is 0.05 , dispersion of the sample is 0.0017 , standard error is 0.04 . As is indicated by the findings, the intensity of changes in the velocity of movements of the earth's crust is not high throughout the territory under examination, with the exception of some regions.

Findings of the research enable us to make the following conclusion: the range of the digital values of vertical movement gradients is quite diverse; however, the territory is dominated by rather moderate values. This allows assuming that the region contains some areas with moderate vertical movement changes. In order 
to pinpoint territories characterised by temperate and regular rising/lowering or intensive rising/lowering, a map of the horizontal gradients of recent vertical movements of the earth's crust in the territory enclosed by Vilnius-Jonava-Zarasai-Turmantas-Vilnius levelling polygon was compiled (as shown in Fig. 6).

Fig. 6 shows particular regions contained within the territory under examination where the rising/lowering of territory is uniform; however, the territory also contains regions in which the changes in recent movements of the earth's crust are rather distinct. In the western part of territory under research, the earth's crust rising is replaced by the earth's crust lowering; in this particular place, fractures are observed; this evidence coincides with increased digital values of modules of recent earth's crust movement gradients observed in this place. Besides, there is a fracture crossing the middle of this territory, and from this place, intensive rising of the territory starts (as shown in Fig. 4); higher digital values of gradients are also observed here.

\section{Discussions and conclusions}

Basing on the findings provided by measuring, vertical movements of the earth's crust and correlated geodetic parameters $(-0.94 \leq R \leq 0.95)$ were computed. Shared relationships between movements and territorial geo-parameters differ along different levelling lines; it is possible to pinpoint regional peculiarities. When making regression models for the prediction of vertical movement velocities it would be worthwhile to take into consideration the specific features of geologic structure and to apply fragment-based simulation; this implies taking separate levelling lines for examination without bringing them together to form a closed polygon.

In order to forecast vertical movements of the earth's crust, regression models adequate to the data provided by measuring were worked out. In all cases, the determination rate exceeded $76 \%, F>F_{q}$, consequently, it is possible to argue, with a probability of $p=1-q \geq 0.95$, that values predicted by regression models are adequate to the vertical earth's crust movement velocity values.

A map of recent vertical earth's crust movement velocities for the territory enclosed by Vilnius-Jonava-Zarasai-Turmantas-Vilnius levelling polygon was compiled; it allows judging the qualities of movements over the past 19-28 years. The amplitude

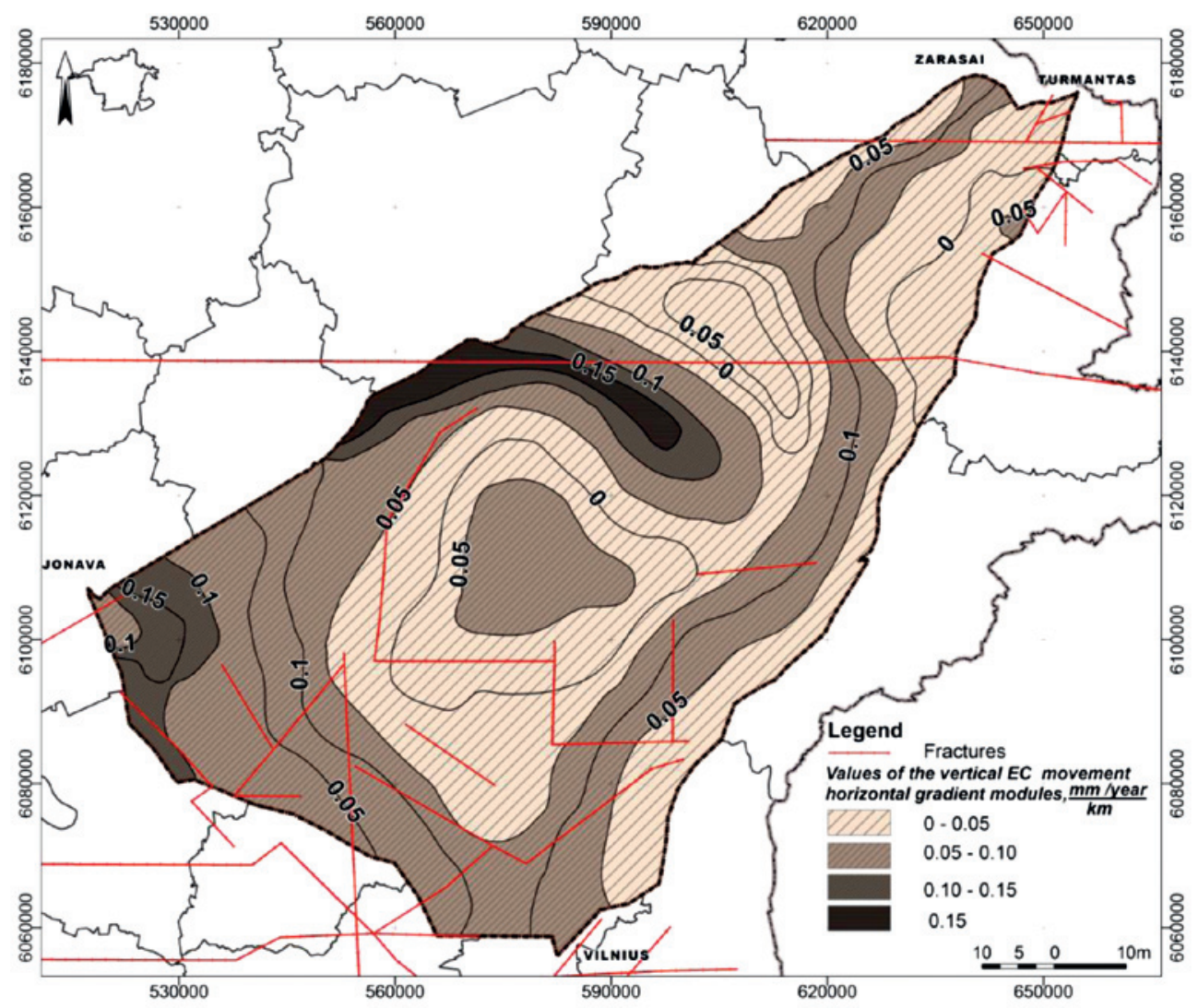

Fig. 6. Modules of horizontal gradients of recent vertical earth's crust movement velocities in Vilnius-Jonava-Zarasai-Turmantas-Vilnius levelling polygon 
of movements ranges from -1.3 to $2.7 \mathrm{~mm} /$ year, the mean value in the territory enclosed by the levelling polygon amounts to $0.66 \mathrm{~mm} /$ year. In the eastern part of the territory, the rising of earth crust takes place, however in the western part the territory, it is moving downwards.

Changes in the digital values of horizontal gradient modules in the territory enclosed by Vilnius-Jonava-Zarasai-Turmantas-Vilnius polygon fluctuate between 0.00006 to $0.20(\mathrm{~mm} /$ year $) / \mathrm{km}$; the mean of digital values of gradients amounts to 0.06 ( $\mathrm{mm} /$ year)/ $\mathrm{km}$. The present research enabled pinpointing areas on the territory in which uniform rising/lowering of the territory takes place as well as areas demonstrating sharp changes in the velocity of movements.

\section{References}

Amoruso, A.; Crescentini, L.; Scarpa, R. 2005. Faulting geometry for the complex 1980 Campania-Lucania earthquake from levelling data, Geophysical Journal International 162: 156168. http://dx.doi.org/10.1111/j.1365-246X.2005.02652.x

Battaglia, M.; Segal, P.; Murray, J.; Cervelli, P.; Langbein, J. 2003a. The mechanics of unrest at Long Valley caldera, California: 1. Modeling the geometry of the source using GPS, levelling and two color EDM data, Journal of Volcanology and Geothermal Research 127: 195-217.

http://dx.doi.org/10.1016/S0377-0273(03)00170-7

Battaglia, M.; Segal, P.; Roberts, C. 2003b. The mechanics of unrest at Long Valley caldera, California: 2. Constraining the nature of the source using geodetic and microgravity data, Journal of Volcanology and Geothermal Research 127: 219-245. http://dx.doi.org/10.1016/S0377-0273(03)00171-9

Behncke, B.; Berrino, G.; Corrado, G.; Velardita, R. 2006. Ground deformation and gravity changes on the island of Pantelleria in the geodynamic framework of the Sicily Chanel, Journal of Volcanology and Geothermal Research 150: 146-162. http://dx.doi.org/10.1016/j.jvolgeores.2005.07.001

Bonaccorso, A. 2002. Ground deformation of the southern sector of the Aeolian islands volcanic arc from geodetic data, Tectonophysics 351: 181-192.

http://dx.doi.org/10.1016/S0040-1951(02)00163-4

Bonaccorso, A.; Mattia, M. 2000. Deflation acting on Pantelleria island (Sicily Cannel) inferred through geodetic data, Earth and Planetary Science Letters 180: 91-101. http://dx.doi.org/10.1016/S0012-821X(00)00156-4

Demoulin, A. 2004. Reconciling geodetic and geological rates of vertical crustal motion in intraplate regions, Earth and Planetary Science Letters 221: 91-101. http://dx.doi.org/10.1016/S0012-821X(04)00110-4

Draper, N. R.; Smith, H. 1998. Applied regression analysis. New York, USA: Wiley.

Fukahata, Y.; Honsho, C.; Matsu'ura, M. 1996. Crustal movements on Shikoku, southwestern Japan, inferred from inversion analysis of levelling data using ABIC, Tectonophysics 257: 239-252.

http://dx.doi.org/10.1016/0040-1951(95)00176-X

Gottsman, J.; Rymer, H.; Berrino, G. 2006. Unrest at the Campi Flegrei caldera (Italy): a critical evaluation of source parameters from geodetic data inversion, Journal of Volcanology and Geothermal Research 150: 132-145.

http://dx.doi.org/10.1016/j.jvolgeores.2005.07.002

Howle, J. F.; Langbein, J. O.; Farrar, D.; Wilkinson, S. K. 2003. Deformation near the Casa Diablo geothermal well field and related processes Long Valley caldera, Eastern California, 1993-2000, Journal of Volcanology and Geothermal Research 127: 365-390.

http://dx.doi.org/10.1016/S0377-0273(03)00177-X

Krumbein, W. C.; Graybill, F. A. 1965. An introduction to statistical models in geology. New York, USA: McGraw-Hill.

Lanari, R.; Berardino, P.; Borgström, S.; Del Gaudio, C.; De Martino, P.; Fornaro, G.; Guarino, S.; Ricciardi, G. P.; Sansosti, E.; Lundgren, P. 2004. The use of IFSAR and classical geodetic techniques for caldera unrest episodes: application to the Campi Flegrei uplift event of 2000, Journal of Volcanology and Geothermal Research 133: 247-260. http://dx.doi.org/10.1016/S0377-0273(03)00401-3

Langbein, J. O. 2003. Deformation of the Long Valley Caldera, California: inferences from measurements from 1988 to 2001, Journal of Volcanology and Geothermal Research 127: 247-267. http://dx.doi.org/10.1016/S0377-0273(03)00172-0

Li, Y. X.; Yang, G. H.; Yang, S. D. 2001. Preliminary division of active block boundary in Chinese mainland based on recent vertical crustal movement, Acta Seismologica Sinica 14: 12-17. http://dx.doi.org/10.1007/s11589-001-0156-6

Mrlina, J. 2000. Vertical displacements in the Nový Kostel seismoactive area, Studia Geophysica et Geodaetica 44: 336-345. http://dx.doi.org/10.1023/A:1022179329713

Newman, A. V.; Dixon, T. H.; Gourmelen, N. 2006. A fourdimensional viscoelastic deformation model for Long Valley Caldera, California, between 1995 and 2000, Journal of Volcanology and Geothermal Research 150: 244-269. http://dx.doi.org/10.1016/j.jvolgeores.2005.07.017

Nielsen, S. B.; Bayer, U. 2003. Dynamics of sedimentary basin inversion: observations and modelling, Tectonophysics 373 : 1-3. http://dx.doi.org/10.1016/S0040-1951(03)00278-6

Rodionov, D. A. 1981. Statistical solutions in geology. Moscow: Nedra (in Russian).

Schwartz, S. Y. 2007. Episodic aseismic slip at plate boundaries, Treatise on Geophysics 4: 445-472. http://dx.doi.org/10.1016/B978-044452748-6/00076-6

Spiegel, M. R.; Stephens, L. J. 2007. Statistics. 4th ed. New York, USA: Mcgraw-Hill.

Tosi, L.; Teatini, P.; Carbognin, L.; Frankenfield, J. 2007. A new project to monitor land subsidence in the northern Venice coastland (Italy), Environmental Geology 52: 889-898. http://dx.doi.org/10.1007/s00254-006-0530-8

Ulomov, V. I. 2004. Implication of horizontal tectonic movements for seismogeodynamics and seismic hazard prediction, Izvestiya, Physics of the Solid Earth 40: 710-724.

Vestol, O. 2006. Determination of postglacial land uplift in Fennoscandia from levelling, tide-gauges and continuous GPS stations using least squares collocation, Journal of Geodesy 80: $248-258$ http://dx.doi.org/10.1007/s00190-006-0063-7

Zakarevicius, A. 1994. The investigation of present vertical movements Earth crust's in the territory of Lithuania. Vilnius: Technika.

Zakarevicius, A. 2003. Investigation of the recent geodynamic processes in the territory of Lithuania. Vilnius: Technika. 
Rūta PUZIENE. Dr Vilnius Gediminas Technical University, Dept of Geodesy and Cadastre, Saulètekio al. 11, LT-10223 Vilnius, Lithuania (tel. +37052744703), e-mail: ruta.puziene@ vgtu.lt. A graduate of Vilnius Gediminas Technical University (Master of science, 2003). Doctor's degree at Vilnius Gediminas Technical University, 2010. Author of over 20 publications.

Research interests: investigation of geodynamic processes, investigations of deformations.

Asta ANIKENIENE. Dr Department of Geodesy, Civil Engineering Faculty, Vilnius University of applied Engineering sciences, Antakalnio str. 54, Vilnius, LT-10303, Lithuania, email: asta.anikeniene@gmail.com. A graduate of Vilnius Gediminas Technical University (Master of science, 2003). Doctor's degree at Vilnius Gediminas Technical University, 2009. Author of over 10 publications.

Research interests: investigation of geodynamic processes, investigations of deformations.

Gitana KORSAKIENE. Master's degree, IH Soros International House, Konstitucijos str. 23, Vilnius, LT-08105, Lithuania, e-mail: gitana.karsokiene@gmail.com 